\title{
BMJ Open Characterising the scale-up and performance of antiretroviral therapy programmes in sub-Saharan Africa: an observational study using growth curves
}

\author{
Benjamin Bigelow (D) , ${ }^{1}$ Stéphane Verguet ${ }^{2}$
}

To cite: Bigelow B, Verguet S. Characterising the scale-up and performance of antiretroviral therapy programmes in sub-Saharan Africa: an observational study using growth curves. BMJ Open 2020;10:e034973. doi:10.1136/ bmjopen-2019-034973

- Prepublication history for this paper is available online. To view these files, please visit the journal online (http://dx.doi. org/10.1136/bmjopen-2019034973).

Received 14 0ctober 2019 Revised 24 July 2020 Accepted 21 August 2020
Check for updates

(C) Author(s) (or their employer(s)) 2020. Re-use permitted under CC BY-NC. No commercial re-use. See rights and permissions. Published by BMJ.

${ }^{1}$ Independent Researcher, Arlington, Virginia, USA

${ }^{2}$ Global Health and Population, Harvard T.H. Chan School of Public Health, Boston, Massachusetts, USA

Correspondence to Dr Stéphane Verguet; verguet@hsph.harvard.edu

\section{ABSTRACT}

Objectives The rate of change in key health indicators (eg, intervention coverage) is an understudied area of health system performance. Rates of change in health services indicators can augment traditional measures that solely involve the absolute level of performance in those indicators. Growth curves are a class of mathematical models that can parameterise dynamic phenomena and estimate rates of change summarising these phenomena; however, they are not commonly used in global health. We sought to characterise the changes over time in antiretroviral therapy (ART) coverage in sub-Saharan Africa using growth curve models.

Design This was a retrospective observational study. We used publicly available data on ART coverage levels from 2000 to 2017 in 42 sub-Saharan African countries. We developed two ordinary differential equations models, the Gompertz and logistic growth models, that allowed for the estimation of summary parameters related to scale-up and rates of change in ART coverage. We fitted non-linear regressions for the two models, assessed goodness of fit using the Bayesian information criterion (BIC), and ranked countries based on their estimated performance drawn from the fitted model parameters.

Results We extracted country performance in rates of scale-up of ART coverage, which ranged from $\leq$ 2.5 percentage points per year (South Sudan, Sudan, and Madagascar) to $\geq 8.0$ percentage points per year (Benin, Zimbabwe and Namibia), using the Gompertz model. Based on BIC, the Gompertz model provided a better fit than the logistic growth model for most countries studied. Conclusions Growth curve models can provide benchmarks to assess country performance in ART coverage evolution. They could be a useful approach that yields summary metrics for synthesising country performance in scaling up key health services.

\section{INTRODUCTION}

Health policy-makers are concerned with measuring the effectiveness, efficiency and overall performance of national health systems in a comparable manner. Measuring performance requires relating the attainment of specific objectives, such as the improvement of population health and of its distribution, to the dedicated financial resources and
Strengths and limitations of this study

- Growth curve models are straightforward to fit to data and could provide intuitive parameters for assessing country performance in health services indicators.

- Since we only analysed data on antiretroviral therapy, the goodness of fit of the growth curve models is limited and would not generalise to other diseases and health services indicators.

- The fitted growth curve models do not incorporate or provide much insight into the country-specific context of HIV epidemiology or local health system priorities.

expenditures in a country. ${ }^{1-3}$ Additionally, comparable data on health system performance provide a foundation for subsequent analyses of variation across countries, ultimately strengthening the evidence base for understanding variations in performance and for policy implementation. ${ }^{1}$ Stakeholders can then use such information to better analyse how performance on stated objectives varies with several factors, including how the health system is organised, financed and regulated. ${ }^{23}$

The question of how to evaluate health system performance is difficult, as it requires choices to be made about what to measure (eg, which outcomes, outputs and costs), how to measure (eg, with which administrative data, household surveys), and how to present the results (eg, with which individual or composite indicators). For example, in its 2000 World Health Report, the WHO defined health system performance along several objectives and then ranked the health systems of WHO member states using statistical modelling. ${ }^{4}$ This generated immediate debate, ${ }^{5-7}$ and a number of researchers subsequently revisited the methodology and the sensitivity behind the rankings. ${ }^{8-10}$ 
Table 1 Mathematical formulations for the Gompertz and logistic growth models

\begin{tabular}{llll}
\hline Model & Differential equation & Original solution & Modified solution \\
\hline Gompertz & $\frac{d y}{d t}=-c y \ln \left(\frac{y}{a}\right)$ & $y(t)=a \cdot \exp [-\exp (b-c t)]$ & $y=A \cdot \exp \left\{-\exp \left[\frac{\mu \cdot e}{A}(\lambda-t)+1\right]\right\}$ \\
Logistic & $y(0)=y_{0}$ & $d y$ \\
& & $y(t)=\frac{a}{1+\exp (b-c t)}$ & $y=\frac{A}{\left\{1+\exp \left[\frac{4 \mu}{A}(\lambda-t)+2\right]\right\}}$ \\
& $y(0)=y_{0}$ & & \\
\hline
\end{tabular}

The modified solutions are adapted from Zwietering et al. ${ }^{18}$ They are equivalent to the canonical solutions provided, but rewritten so as to be interpretable in a global health context.

Antiretroviral therapy (ART) coverage (in percentage points) is represented by $y$. The dependent variables represent the lag or delay time ( $\lambda$, in years since 2000), the maximum scale-up rate of ART coverage ( $\mu$, in percentage points per year), and the carrying capacity of ART coverage ( $A$, in percentage points).

A step towards understanding country performance in health could lie in the examination of the evolution over time of specific health outcomes and health services indicators. However, many health indicators focus on the absolute level of performance. The United Nations' Millennium Development Goals, for example, included health outcomes such as the maternal mortality ratio and the incidence of malaria, two indicators that capture performance at a single point in time. ${ }^{11}$ Similarly, UNAIDS developed performance indicator levels into its recent 90-90-90 treatment targets for tackling the AIDS epidemic by $2030 .{ }^{12}$ Yet, only evaluating the levels of performance for certain outcomes can ignore longstanding determinants within countries that may affect the ability to expand access to care. It may also blur the ability of researchers to understand performance variation across countries. In this respect, examining the rates of change of health services indicators may prove valuable in understanding the performance of national policies and programmes. ${ }^{13-15}$ As a case in point, in Good Health at Low Cost: 25 Years On, Balabanova et al ${ }^{16}$ used both levels and rates of changes of health outcomes and services

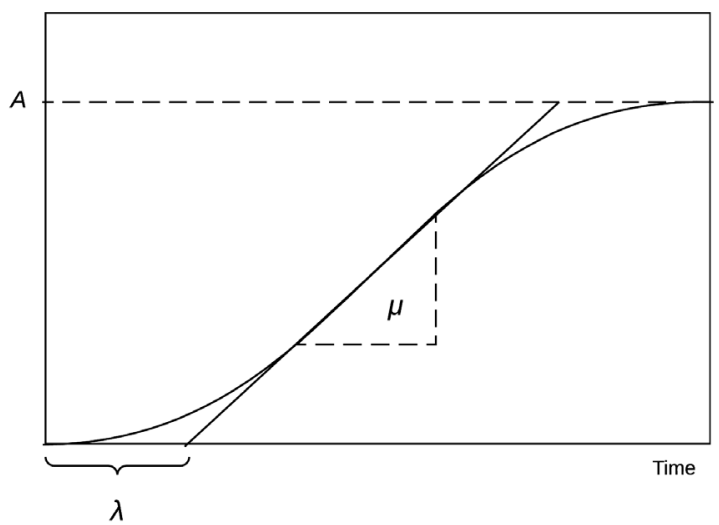

Figure 1 Diagram depicting a basic growth curve and its associated parameterisation. Note: this figure is adapted from Zwietering et al. ${ }^{18} A$ is the carrying capacity, $\mu$ is the maximum growth rate and $\lambda$ is the lag time. coverage to select which countries to study as relevant examples of good performance in health.

Rates of change in coverage of health services can be estimated empirically (eg, by taking the first derivative of coverage), but their evolution over time can also be captured by mathematical models, including simple ordinary differential equations such as growth curves. Indeed, growth curves have been used in numerous other academic disciplines to model specific dynamic phenomena, and they could yield meaningful summary parameters that characterise intervention scale-up. For example, in telecommunications, the Bass diffusion equation models the spread of innovation or adoption of new technologies in a population ${ }^{17}$; and in cell biology, growth curves can be used to represent bacterial growth. ${ }^{18}$ Despite these common uses, such differential equation models have not been widely implemented in global public health.

Growth curve models could parameterise and capture the evolution of health services coverage over time. In this paper, we illustrate the relevance of growth curves by attempting to characterise and parameterise the growth in antiretroviral therapy (ART) coverage in 42 sub-Saharan African countries using two long-established growth models: the logistic and the Gompertz models. We then extract summary metrics (eg, rate of scale-up, time delay to scale-up) that describe the evolution of ART coverage and thus may be of use to analysts interested in understanding cross-country variation in ART coverage evolution in sub-Saharan Africa.

\section{METHODS \\ Data sources}

We used country-level data on ART coverage from 2000 to 2017 from the World Bank's World Development Indicators database; these data were originally sourced from UNAIDS estimates. ${ }^{19}$ ART coverage is defined as the percentage of people living with HIV who are receiving ART; the numerator (ie, the number of people on ART) is aggregated at the country level, and UNAIDS models generate the denominator (ie, the population living with 

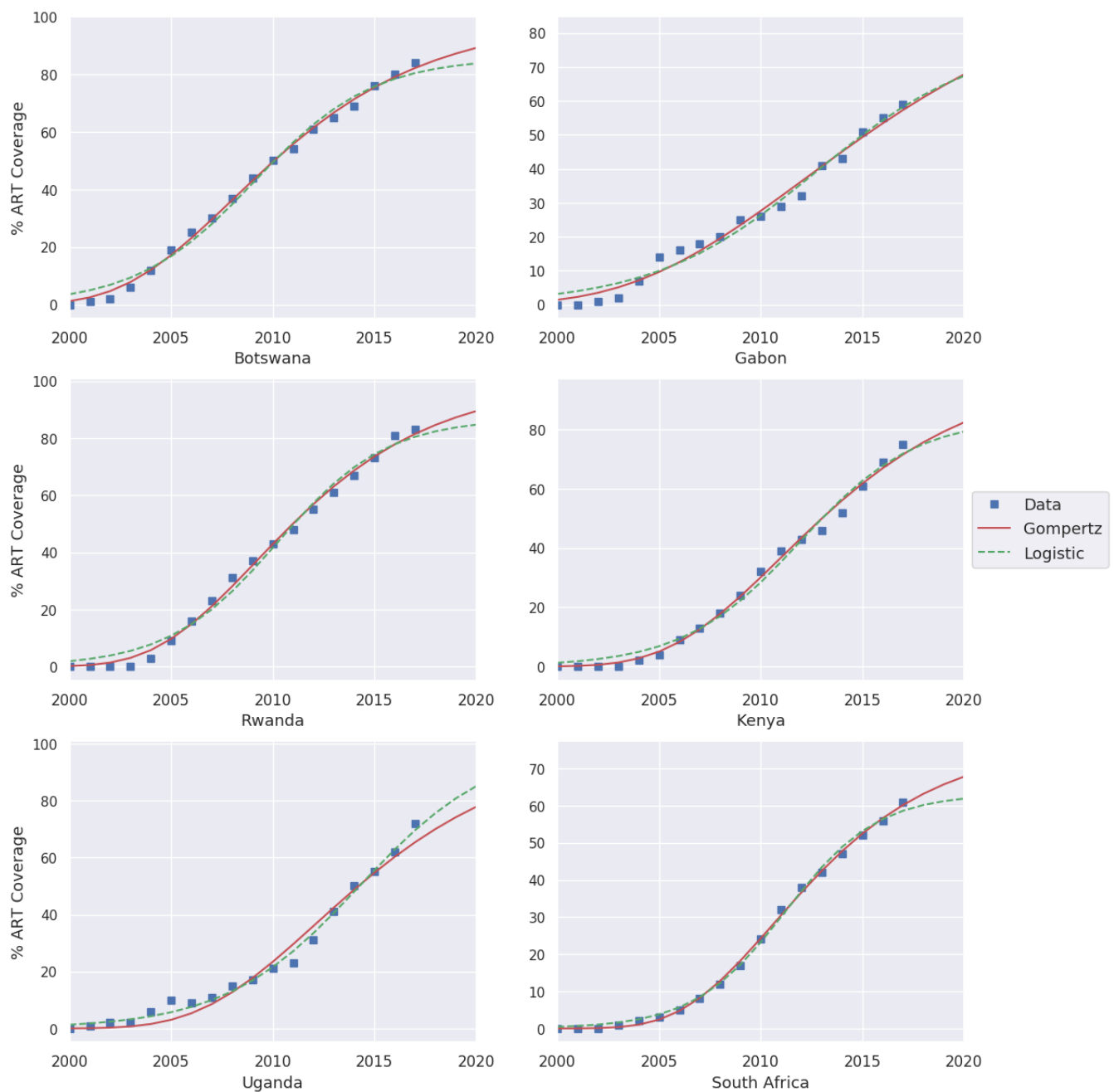

Figure 2 Growth curve fits over the time period 2000-2017 for six selected sub-Saharan African countries: Botswana, Gabon, Rwanda, Kenya, Uganda and South Africa. ART, antiretroviral therapy.

HIV).$^{20-22}$ We limited our analysis to sub-Saharan Africa, the region most impacted by HIV: according to UNAIDS, it accounted for close to $70 \%$ of all people living with HIV in 2018. ${ }^{23}$ We further limited our analysis to countries with a population exceeding one million, ${ }^{24}$ leading to a sample of 42 sub-Saharan African countries.

\section{Mathematical approach}

We used two types of ordinary differential equations to model the growth in ART coverage over time in the selected countries: the logistic and the Gompertz equations (table 1). In their canonical forms, these models are not easily interpretable in a global health context. ${ }^{18}$ Therefore, we used the transformations described by Zwietering et al for both the Gompertz and logistic equations. ${ }^{18}$ The derived parameters (see 'modified solutions') have an intuitive interpretation: $A$ represents the projected maximum level of intervention coverage (in percentage points); $\mu$ the maximum growth or maximum scale-up rate of intervention coverage (in percentage points per year); and $\lambda$ the lag or delay time prior to the start of the intervention implementation (in years). The initial level of intervention coverage is represented by $y_{0}$ (figure 1 provides a graphical representation).

The logistic equation is a simple and widely used growth curve model. Though its simplicity is advantageous, it may not be well suited to model coverage scale-up and evolution, especially since it is symmetric in shape. The maximum growth rate (ie, the slope at the inflection point of the coverage curve) occurs halfway between the initial value $\left(y_{0}\right)$ and the asymptotic carrying capacity $(A)$. There is no a priori reason to believe that growth in ART coverage over time would be symmetric or that the highest rate of growth would be exactly halfway between these two points (ie, the start and end points). Unlike the logistic equation, the Gompertz equation allows for asymmetry, as the maximum growth rate need not occur exactly halfway between $y_{0}$ and $A$. This property may better fit with the study of ART coverage evolution over time: coverage may grow rapidly in the initial stages of a programme, but marginal gains in later stages may be 


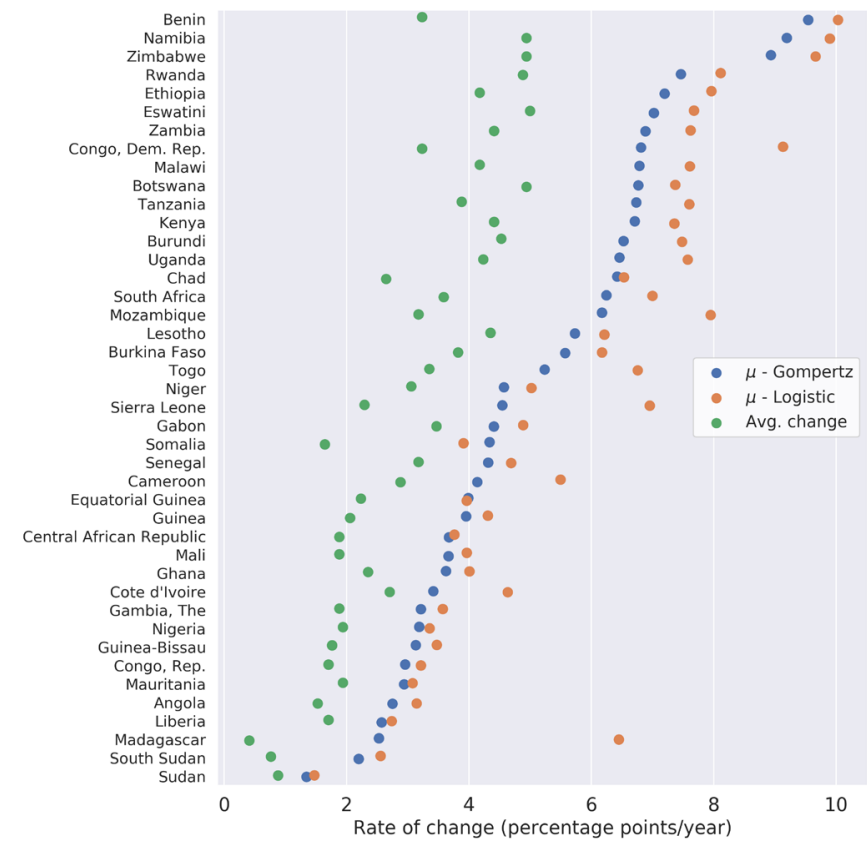

Figure 3 Estimated maximum rate of change in antiretroviral therapy (ART) coverage (denoted $\mu$, maximum estimated rate of scale-up in percentage points per year) for 42 sub-Saharan African countries, for the Gompertz and logistic models. The countries are ranked according to $\mu$ estimates from the Gompertz model. Note: the 'average change' (2017 ART coverage divided by the number of years since ART coverage $>0$ ) green dots display the observed crude average rate of change of the entire 2000-2017 time period.

difficult to achieve. Exponential growth at low values of time $(t)$ and the gradual approach of an asymptote could be desirable properties in modelling coverage evolution and programme scale-up (exponential growth is linear on a $\log$ scale, and $\ln (y)$ for both the Gompertz and logistic models is linearly proportional to $t$ for low values of $t$ ). Therefore, we retained both the Gompertz and logistic growth models in our study.

\section{Model estimation}

We fitted both growth models to ART coverage time series data using nonlinear regression methods. All the analyses were performed with the Python programming language; for the nonlinear regressions, we used the LMFIT package, which implements the Levenberg-Marquardt algorithm for least-squares minimisation. ${ }^{25}$ The goodness of the model fits were then assessed using the Bayesian information criterion (BIC). ${ }^{26}$

In addition, we compared the estimated parameters to values directly observed from the data: an observed lag time was calculated as the number of years between 2000 (when data were first available) and a country's first year with ART coverage $>0$. We also considered the observed (crude) average change in ART coverage, defined as current ART coverage divided by the number of years since ART coverage $>0$.
Patient and public involvement

No patients were involved in this study.

\section{RESULTS}

We first display the fits of the Gompertz and logistic growth models to the data of six selected sub-Saharan African countries (figure 2), along with the estimated maximum rates of change (rates of scale-up, denoted $\mu$ ) across all the countries examined (figure 3 ).

With the Gompertz growth curve, across all countries in the sample, the mean value of $\mu$ was 5.1 percentage points per year, with a range from 1.3 percentage points per year (Sudan) to 9.5 percentage points per year (Benin). For the logistic growth curve, estimates of $\mu$ ranged from 1.5 percentage points per year (Sudan) to 10.0 percentage points per year (Benin), with a mean value of 5.8 percentage points per year. Country-specific estimates from the Gompertz and logistic growth models tended to cluster near similar values (figure 3 ). Still, there were a few countries where estimates of $\mu$ diverged. For example, for Madagascar, the Gompertz growth model estimated $\mu=2.5$ percentage points per year, whereas the logistic growth model estimated $\mu=6.5$ percentage points per year; for Sierra Leone, 4.5 percentage points per year for the Gompertz versus 7.0 for the logistic. However, Madgascar and Sierra Leone stand out as singular cases as both countries have relatively low HIV prevalence $(0.3 \%$ and $1.5 \%$ of the adult population, respectively ${ }^{27}$ ); and Madagascar had ART coverage levels below 10\%, which thus makes it difficult to model ART coverage scale-up ${ }^{19}$ given the relatively low changes in coverage magnitude over time.

Table 2 shows the estimated rates of change per country along with an associated ranking. For a majority of countries, the rankings were similar across Gompertz versus logistic growth curves. For example, Benin remained a top performer, while Sudan remained a bottom performer. In between, however, the rankings were less stable. For example, when examining the observed crude average rate of change over the 2000-2017 time period (defined as current ART coverage divided by the number of years since ART coverage $>0$ ), Benin ranked 18th, while it ranked 1st on the estimated $\mu$ from the logistic growth model; Botswana ranked 2nd under the observed crude average rate of change over the 2000-2017 time period and 14th under the estimated $\mu$ from the logistic growth model. Overall, correlation of ranks on $\mu$ was 0.94 between the logistic and Gompertz models; 0.87 between Gompertz's $\mu$ and the observed crude average rate of change; and 0.79 between logistic's $\mu$ and the observed crude average rate of change. These differences also come from the fact that average rates of change (over the entire 2000-2017 time period) and maximum rates of change capture two different coverage evolution phenomena.

As for time delays, the estimated mean value (across all countries in the sample) of $\lambda$ was 6.5 years with the Gompertz growth model compared with 7.3 years with 
Table 2 Estimated maximum rate of change in antiretroviral therapy (ART) coverage (denoted $\mu$, maximum estimated rate of scale-up in percentage points per year) for 42 sub-Saharan African countries, and corresponding ranks (across all countries in the sample), for the Gompertz and logistic models

\begin{tabular}{|c|c|c|c|c|c|c|}
\hline \multirow[b]{2}{*}{ Country } & \multicolumn{2}{|c|}{ Gompertz } & \multicolumn{2}{|c|}{ Logistic } & \multirow{2}{*}{$\begin{array}{l}\text { Observed crude } \\
\text { average change }\end{array}$} & \multirow[b]{2}{*}{ Rank } \\
\hline & $\mu$ & Rank & $\mu$ & Rank & & \\
\hline Angola & 2.8 & 38 & 3.1 & 38 & 1.5 & 39 \\
\hline Benin & 9.5 & 1 & 10.0 & 1 & 3.2 & 18 \\
\hline Botswana & 6.8 & 10 & 7.4 & 14 & 4.9 & 2 \\
\hline Burkina Faso & 5.6 & 19 & 6.2 & 22 & 3.8 & 14 \\
\hline Burundi & 6.5 & 13 & 7.5 & 13 & 4.5 & 6 \\
\hline Cameroon & 4.1 & 26 & 5.5 & 23 & 2.9 & 23 \\
\hline Central African Republic & 3.7 & 29 & 3.8 & 33 & 1.9 & 32 \\
\hline Chad & 6.4 & 15 & 6.5 & 19 & 2.6 & 25 \\
\hline Congo, Dem. Rep. & 6.8 & 8 & 9.1 & 4 & 3.2 & 18 \\
\hline Congo, Rep. & 3.0 & 36 & 3.2 & 37 & 1.7 & 36 \\
\hline Cote d'Ivoire & 3.4 & 32 & 4.6 & 27 & 2.7 & 24 \\
\hline Equatorial Guinea & 4.0 & 27 & 4.0 & 31 & 2.2 & 28 \\
\hline Eswatini & 7.0 & 6 & 7.7 & 8 & 5.0 & 1 \\
\hline Ethiopia & 7.2 & 5 & 8.0 & 6 & 4.2 & 11 \\
\hline Gabon & 4.4 & 23 & 4.9 & 25 & 3.5 & 16 \\
\hline Gambia, The & 3.2 & 33 & 3.6 & 34 & 1.9 & 32 \\
\hline Ghana & 3.6 & 31 & 4.0 & 29 & 2.4 & 26 \\
\hline Guinea & 4.0 & 28 & 4.3 & 28 & 2.1 & 29 \\
\hline Guinea-Bissau & 3.1 & 35 & 3.5 & 35 & 1.8 & 35 \\
\hline Kenya & 6.7 & 12 & 7.4 & 15 & 4.4 & 7 \\
\hline Lesotho & 5.7 & 18 & 6.2 & 21 & 4.4 & 9 \\
\hline Liberia & 2.6 & 39 & 2.7 & 40 & 1.7 & 36 \\
\hline Madagascar & 2.5 & 40 & 6.5 & 20 & 0.4 & 42 \\
\hline Malawi & 6.8 & 9 & 7.6 & 10 & 4.2 & 11 \\
\hline Mali & 3.7 & 30 & 4.0 & 30 & 1.9 & 32 \\
\hline Mauritania & 2.9 & 37 & 3.1 & 39 & 1.9 & 30 \\
\hline Mozambique & 6.2 & 17 & 8.0 & 7 & 3.2 & 20 \\
\hline Namibia & 9.2 & 2 & 9.9 & 2 & 4.9 & 2 \\
\hline Niger & 4.6 & 21 & 5.0 & 24 & 3.1 & 22 \\
\hline Nigeria & 3.2 & 34 & 3.4 & 36 & 1.9 & 30 \\
\hline Rwanda & 7.5 & 4 & 8.1 & 5 & 4.9 & 5 \\
\hline Senegal & 4.3 & 25 & 4.7 & 26 & 3.2 & 20 \\
\hline Sierra Leone & 4.5 & 22 & 7.0 & 17 & 2.3 & 27 \\
\hline Somalia & 4.3 & 24 & 3.9 & 32 & 1.6 & 38 \\
\hline South Africa & 6.2 & 16 & 7.0 & 16 & 3.6 & 15 \\
\hline South Sudan & 2.2 & 41 & 2.6 & 41 & 0.8 & 41 \\
\hline Sudan & 1.3 & 42 & 1.5 & 42 & 0.9 & 40 \\
\hline Tanzania & 6.7 & 11 & 7.6 & 11 & 3.9 & 13 \\
\hline Togo & 5.2 & 20 & 6.8 & 18 & 3.4 & 17 \\
\hline Uganda & 6.5 & 14 & 7.6 & 12 & 4.2 & 10 \\
\hline Zambia & 6.9 & 7 & 7.6 & 9 & 4.4 & 7 \\
\hline Zimbabwe & 8.9 & 3 & 9.7 & 3 & 4.9 & 2 \\
\hline
\end{tabular}

The 'observed crude average change' (2017 ART coverage divided by the number of years since ART coverage $>0$ ) displays the observed crude average rate of change over the entire 2000-2017 time period. 


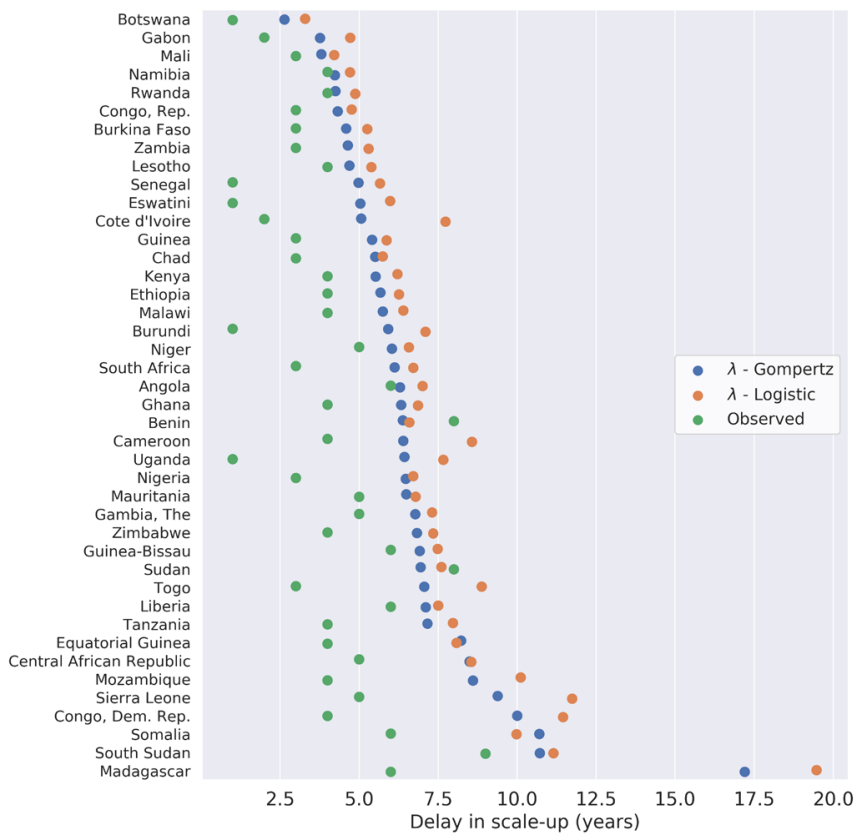

Figure 4 Estimated time delays in antiretroviral therapy (ART) coverage scale-up (denoted $\lambda$ in years) for 42 subSaharan African countries, for the Gompertz and logistic models. The countries are ranked according to $\lambda$ estimates from the Gompertz model. Note: the 'observed' time delay green dots correspond to the lag time calculated as the number of years between 2000 and a country's first year with ART coverage $>0$.

the logistic growth model (figure 4). Some of the differences between the observed (number of years between 2000 and a country's first year with ART coverage $>0$ ) and estimated delays occur in a small group of countries such as Madagascar and Somalia, countries which tend to have low levels of both ART coverage and HIV prevalence, making it difficult to model ART coverage evolution given the relatively low changes in coverage magnitude over time. For example, in 2017, Madagascar had an HIV prevalence of $0.3 \%$ and ART coverage of $7 \%$; for Sudan, it was $0.1 \%$ and $28 \%$, respectively. ${ }^{19} 27$

Botswana presented the shortest estimated delay to scale-up $(\lambda)$ from both models (2.6 years for the Gompertz model and 3.3 years for the logistic model). Contrarily, Madagascar showed the longest estimated delay in scale-up (19.5 and 17.2 years according to the Gompertz and logistic growth models, respectively; table 3). Country rankings were dependent on the way lag time $\lambda$ was estimated. A few countries, such as Botswana (ranked 1st) and Senegal (ranked 10th), retained their ranking across the Gompertz and logistic growth cruves. Others saw important changes, such as Côte d'Ivoire, ranked 12th with $\lambda$ estimated from the Gompertz growth model compared with 31st with $\lambda$ estimated from the logistic model. Overall, correlation in ranks on $\lambda$ between the logistic and Gompertz growth models was 0.97 ; while it was 0.53 between Gompertz's $\lambda$ and the observed time delay, and 0.53 between the logistic estimates of $\lambda$ and the observed time delay.
In evaluating the goodness of fit of each growth model, we sought the model with the lowest BIC. ${ }^{28}$ For this comparison, across countries, we subtracted the BIC of the logistic growth model from the BIC of the Gompertz model, and calculated $\triangle \mathrm{BIC}$. When $\triangle \mathrm{BIC}>6$, the logistic growth model would be supported; when $\triangle \mathrm{BIC}<-6$, the Gompertz growth model would be supported. ${ }^{28}$ Our findings were then split between the two models, with the Gompertz model generally providing a better fit for most countries. Differences in BIC ranged from 22 for Uganda to -26 for Malawi (figure 5).

\section{DISCUSSION}

In this paper, we used two simple and intuitive differential equations, the logistic and the Gompertz growth curves, to characterise changes in ART coverage over 2000-2017 for 42 sub-Saharan African countries. Using nonlinear regressions, we estimated key parameters to describe ART coverage evolution, including the maximum rate of change ( $\mu$ in percentage points per year) and the lag time to coverage scale-up ( $\lambda$ in years). We were then able to compare these estimated parameters to observed ART coverage data to describe how ART performance and scale-up varies across sub-Saharan African countries.

Some countries performed consistently well across growth models. For example, Botswana was the highest ranking country across all estimated parameters for the time delay in ART scale-up ( $\lambda$ ), and also ranked well for its estimates in maximum rates of change of scale-up $(\mu)$. This reflects the success Botswana achieved in scaling up its ART programme. Since 2002, Botswana has committed significant resources to establishing universal coverage for ART; consequently, mortality among people living with HIV in the country fell dramatically. ${ }^{29}{ }^{30}$ Likewise, Rwanda is another success story highlighted here; it ranks fifth in the estimated delay in ART scale-up (4.3 years with the Gompertz model) and fourth in the estimated maximum rate of change (7.5 percentage points per year, with the Gompertz model). Although few people living with HIV were being treated back in 2003, the country had already achieved, by 2017, ART coverage levels greater than $80 \% .{ }^{31}$ On the contrary, South Africa demonstrated a significant delay in ART scale-up (around 6-7 years as estimated by each growth model), consistent with the evolution of national ART coverage and the postponing of ART scale-up in the country. ${ }^{32}$ After 2006, when ART coverage was then at $4 \%$, South Africa significantly grew its ART programme and achieved rapid coverage expansion of approximately 1.8 million people by 2011 and over 3 million people by 2017, for a current ART coverage of about $61 \% .^{33}{ }^{34}$ Therefore, our growth models and their estimates of maximum rates of change and time delays could provide analysts with useful summary indicators for characterising the evolution over time of key health services (ART in our case study here).

Nevertheless, our analysis presents a number of limitations. First, our approach cannot be generalisable as we 
Table 3 Estimated time delay in antiretroviral therapy (ART) coverage scale-up (denoted $\lambda$ in years) for 42 sub-Saharan African countries, and corresponding ranks (across all countries in the sample), for the Gompertz and logistic models

\begin{tabular}{|c|c|c|c|c|c|c|}
\hline \multirow[b]{2}{*}{ Country } & \multicolumn{2}{|c|}{ Gompertz } & \multicolumn{2}{|l|}{ Logistic } & \multirow{2}{*}{$\begin{array}{l}\text { Observed crude } \\
\text { delay }\end{array}$} & \multirow[b]{2}{*}{ Rank } \\
\hline & $\lambda$ & Rank & $\lambda$ & Rank & & \\
\hline Angola & 6.3 & 21 & 7.0 & 23 & 6 & 35 \\
\hline Benin & 6.4 & 23 & 6.6 & 18 & 8 & 40 \\
\hline Botswana & 2.6 & 1 & 3.3 & 1 & 1 & 1 \\
\hline Burkina Faso & 4.6 & 7 & 5.3 & 7 & 3 & 8 \\
\hline Burundi & 5.9 & 18 & 7.1 & 24 & 1 & 1 \\
\hline Cameroon & 6.4 & 24 & 8.6 & 35 & 4 & 17 \\
\hline Central African Republic & 8.5 & 36 & 8.6 & 34 & 5 & 30 \\
\hline Chad & 5.5 & 14 & 5.7 & 11 & 3 & 8 \\
\hline Congo, Dem. Rep. & 10.0 & 39 & 11.5 & 40 & 4 & 17 \\
\hline Congo, Rep. & 4.3 & 6 & 4.8 & 5 & 3 & 8 \\
\hline Cote d'Ivoire & 5.1 & 12 & 7.7 & 31 & 2 & 6 \\
\hline Equatorial Guinea & 8.2 & 35 & 8.1 & 33 & 4 & 17 \\
\hline Eswatini & 5.0 & 11 & 6.0 & 13 & 1 & 1 \\
\hline Ethiopia & 5.7 & 16 & 6.3 & 15 & 4 & 17 \\
\hline Gabon & 3.8 & 2 & 4.7 & 4 & 2 & 6 \\
\hline Gambia, The & 6.8 & 28 & 7.3 & 25 & 5 & 30 \\
\hline Ghana & 6.3 & 22 & 6.9 & 22 & 4 & 17 \\
\hline Guinea & 5.4 & 13 & 5.9 & 12 & 3 & 8 \\
\hline Guinea-Bissau & 6.9 & 30 & 7.5 & 27 & 6 & 35 \\
\hline Kenya & 5.5 & 15 & 6.2 & 14 & 4 & 17 \\
\hline Lesotho & 4.7 & 9 & 5.4 & 9 & 4 & 17 \\
\hline Liberia & 7.1 & 33 & 7.5 & 28 & 6 & 35 \\
\hline Madagascar & 17.2 & 42 & 19.5 & 42 & 6 & 35 \\
\hline Malawi & 5.7 & 17 & 6.4 & 16 & 4 & 17 \\
\hline Mali & 3.8 & 3 & 4.2 & 2 & 3 & 8 \\
\hline Mauritania & 6.5 & 27 & 6.8 & 21 & 5 & 30 \\
\hline Mozambique & 8.6 & 37 & 10.1 & 38 & 4 & 17 \\
\hline Namibia & 4.2 & 4 & 4.7 & 3 & 4 & 17 \\
\hline Niger & 6.0 & 19 & 6.6 & 17 & 5 & 30 \\
\hline Nigeria & 6.5 & 26 & 6.7 & 19 & 3 & 8 \\
\hline Rwanda & 4.3 & 5 & 4.9 & 6 & 4 & 17 \\
\hline Senegal & 5.0 & 10 & 5.7 & 10 & 1 & 1 \\
\hline Sierra Leone & 9.4 & 38 & 11.7 & 41 & 5 & 30 \\
\hline Somalia & 10.7 & 40 & 10.0 & 37 & 6 & 35 \\
\hline South Africa & 6.1 & 20 & 6.7 & 20 & 3 & 8 \\
\hline South Sudan & 10.7 & 41 & 11.1 & 39 & 9 & 42 \\
\hline Sudan & 6.9 & 31 & 7.6 & 29 & 8 & 40 \\
\hline Tanzania & 7.2 & 34 & 8.0 & 32 & 4 & 17 \\
\hline Togo & 7.1 & 32 & 8.9 & 36 & 3 & 8 \\
\hline Uganda & 6.4 & 25 & 7.7 & 30 & 1 & 1 \\
\hline Zambia & 4.6 & 8 & 5.3 & 8 & 3 & 8 \\
\hline Zimbabwe & 6.8 & 29 & 7.3 & 26 & 4 & 17 \\
\hline
\end{tabular}

The 'observed crude' time delay corresponds to the lag time calculated as the number of years between 2000 and a country's first year with ART coverage $>0$. 


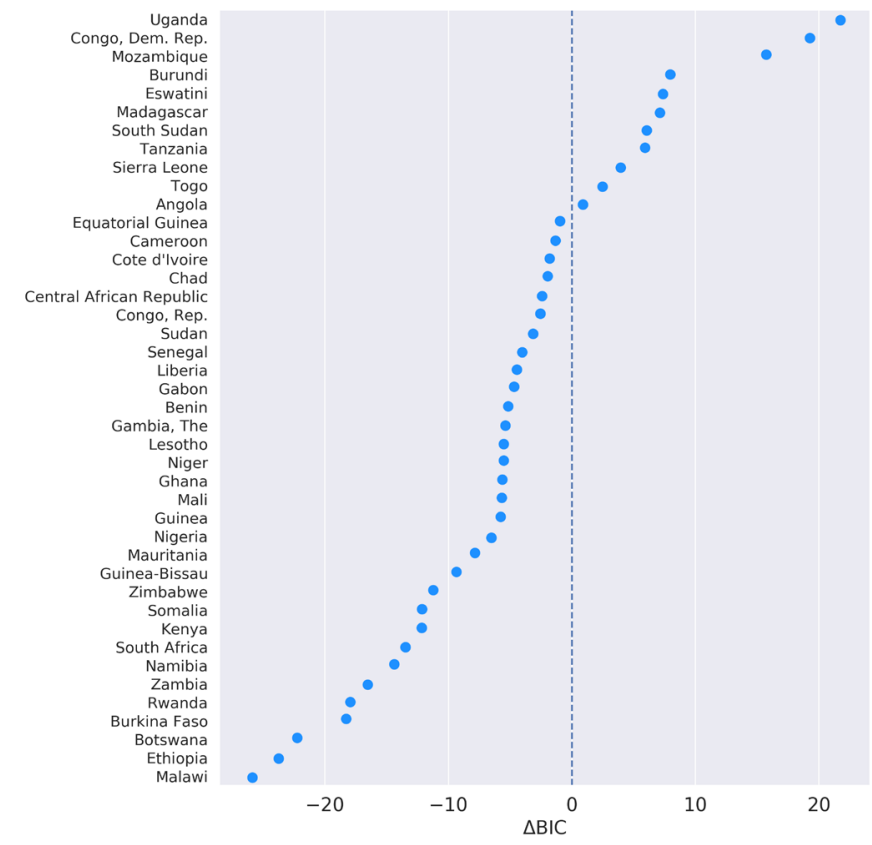

Figure 5 Difference in Bayesian information criterion (BIC) values between the Gompertz and logistic models for 42 subSaharan African countries, ranked from highest to lowest BIC values.

have only tested it with time series data on ART coverage in sub-Saharan Africa. It is important to note that until recently, patients would only receive ART after meeting certain eligibility criteria (eg, CD4 cell counts), and that patients who did not meet these criteria would wait to receive ART. Additionally, although ART may be important in tackling the AIDS epidemic, there are other health services that could be studied for addressing HIV/ AIDS. Most importantly, the scale-up of ART programmes could differ from the provision and scale-up of general health services; for example, general health services may be more freely accessible and/or depend less on development assistance. However, when applied to relevant health services indicators, growth curve models could be adapted to analyse progress in other disease areas and conditions (eg, introduction of a new drug or new vaccine).

Second, our time series coverage data may also be subject to correlations between countries and within country, and one could potentially refine the statistical modelling by introducing country-specific and time-specific random effects. Although an estimated rate of change $(\mu)$ and estimated time delay $(\lambda)$ may be useful to summarise intervention scale-up evolution, they are merely two simple indicators: many factors influence intervention scale-up, and thus $\mu$ and $\lambda$ can in no way answer the fundamental question of why a country might perform well or poorly in one of its programme; $\mu$ and $\lambda$ likely encapsulate many parts of a complex health system architecture, which requires further in-depth investigation.

Third, the UNAIDS ART coverage data used for this analysis were themselves derived from modelled estimates, such as country-specific numbers of people living with HIV. ${ }^{20}{ }^{21}$ Although these models estimate lower and upper limits of uncertainty, we chose to fit our models to the best estimates of ART coverage. By fitting regression models in this way, we may compound their inherent uncertainty. Also, the ART coverage data could be rounded to the nearest whole number, ${ }^{20}{ }^{21}$ which would lead to complications in the interpretation of our estimated country-specific time delays. Finally, the first year of non-zero ART coverage might reflect data collection practices rather than the true start of programme implementation. ${ }^{2021}$ Due to these sources of uncertainty, we emphasise the potential utility of these performance evaluation methods, and would advise caution when interpreting our results against the actual state of ART care in sub-Saharan Africa.

Fourth, our growth models did not incorporate any information on specific country contexts. In some countries, such as Burkina Faso and the Democratic Republic of the Congo, less than $1 \%$ of the population suffer from $\mathrm{HIV}^{27}$; this may explain some of the poor regression fits, for either one or both of the growth models. In contrast, adult prevalence of HIV is near or above $20 \%$ in South Africa, Swaziland and Botswana. ${ }^{27}$ Clearly, the latter group of countries faces different challenges to HIV management and ART scale-up than the former. Lastly, since the structure of health financing can differ significantly across countries, differences in the structure of ART programmes across countries could reflect this heterogeneity as well.

In summary, our growth models were purposely simple and non-mechanistic (eg, no inclusion of HIV transmission dynamics) as they did not rely on existing frameworks for health system analysis. Notably, the information gleaned from our modelling approach should be augmented with the economic and historical context of a given country. As Balabanova et al point out, ${ }^{16}$ the ability of a health system to scale-up an intervention (ie, to achieve a high rate of change or a low lag time) is influenced by the system's history and development. Our objective in this paper is to present a simple approach to estimate meaningful parameters that can summarise health services scale-up, which may be a useful step towards characterising and understanding performance of national disease-specific programmes.

To conclude, our analysis intends to contribute to the growing acknowledgement that rates of change in health outcomes and health services coverage may provide helpful insight into the understanding of country performance on health. Although they are only a starting point, growth curves and basic differential equation models can provide a novel perspective on the scale-up of key interventions in global health.

Acknowledgements The authors thank Osondu Ogbuoji for sourcing preliminary time series data used in this analysis and for useful discussions.

Contributors BB contributed to the data analysis and led the manuscript writing. SV contributed to research design, the interpretation of data, and the revision of the 
manuscript. Both authors critically revised the content of the paper, approved the final version and agree to be accountable for all aspects of the work.

Funding Funding was received from the Department of Global Health and Population, Harvard T.H. Chan School of Public Health.

Disclaimer The views expressed in this article are those of the authors and are not the official positions of their affiliate institutions or funders.

Competing interests BB is currently employed by Hospital IQ (Newton, MA), a healthcare software company. As part of his employment package, $B B$ has received stock options from Hospital IQ; BB also owns stock in CareJourney (Arlington, VA), another healthcare software company. The majority of research, data analysis, and manuscript preparation occurred while BB was at Harvard University, prior to his employment at Hospital IQ. SV has no conflicts of interest to declare.

Patient and public involvement Patients and/or the public were not involved in the design, or conduct, or reporting, or dissemination plans of this research.

Patient consent for publication Not required.

Provenance and peer review Not commissioned; externally peer reviewed.

Data availability statement Data are available in a public, open access repository. Data are available upon reasonable request. All source data are publicly available from the World Bank: https://data.worldbank.org/. The data and code for the analysis can be accessed from the manuscript's GitHub repository: https://github. com/bbig3831/growth-curves.

Open access This is an open access article distributed in accordance with the Creative Commons Attribution Non Commercial (CC BY-NC 4.0) license, which permits others to distribute, remix, adapt, build upon this work non-commercially, and license their derivative works on different terms, provided the original work is properly cited, appropriate credit is given, any changes made indicated, and the use is non-commercial. See: http://creativecommons.org/licenses/by-nc/4.0/.

ORCID iD

Benjamin Bigelow http://orcid.org/0000-0001-6962-3861

\section{REFERENCES}

1 Murray CJ, Frenk J. A framework for assessing the performance of health systems. Bull World Health Organ 2000;78:717-31.

2 Roberts M, Hsiao W, Berman P, et al. Getting health reform right: a guide to improving performance and equity. Oxford University Press, 2008.

3 Smith PC, Mossialos E, Papnicolas I, et al. Performance measurement for health system improvement: experiences, challenges and prospects. 1 ed. Cambridge, New York: Cambridge University Press, 2010.

4 World Health Orgnization. The world health report 2000 - Health systems: improving performance. Geneva, Switzerland: World Health Organization, 2000. http://www.who.int/whr/2000/en/

5 Almeida C, Braveman P, Gold MR, et al. Methodological concerns and recommendations on policy consequences of the world health report 2000. Lancet 2001;357:1692-7.

6 Jamison DT, Sandbu ME. WHO ranking of health system performance. Science 2001;293:1595-6.

7 Musgrove P. Judging health systems: reflections on WHO's methods. Lancet 2003;361:1817-20.

8 Blendon RJ, Kim M, Benson JM. The public versus the World Health Organization on health system performance. Health Aff 2001;20:10-20.

9 Navarro V. The world health report 2000: can health care systems be compared using a single measure of performance? Am J Public Health 2002;92:31-4.

10 Nolte E, McKee M. Measuring the health of nations: analysis of mortality amenable to health care. BMJ 2003;327:1129.
11 United Nations. United Nations millennium development goals. Available: https://www.un.org/millenniumgoals/ [Accessed $13 \mathrm{Apr}$ 2020].

12 UNAIDS. 90-90-90: an ambitious treatment target to help end the AIDS epidemic, 2014. UNAIDS. Available: http://www.unaids.org/ sites/default/files/media_asset/90-90-90_en.pdf [Accessed 22 Oct 2017].

13 Verguet S, Jamison DT. Estimates of performance in the rate of decline of under-five mortality for 113 low- and middle-income countries, 1970-2010. Health Policy Plan 2014;29:151-63.

14 Verguet S, Jamison DT. Performance in rate of decline of adult mortality in the OECD, 1970-2010. Health Policy 2013;109:137-42.

15 Verguet S, Norheim OF, Olson ZD, et al. Annual rates of decline in child, maternal, HIV, and tuberculosis mortality across 109 countries of low and middle income from 1990 to 2013: an assessment of the feasibility of post-2015 goals. Lancet Glob Health 2014;2:e698-709.

16 Balabanova D, McKee M, Mills A. "Good health at low cost" 25 years on: What makes a succesful health system? London: The London School of Hygiene \& Tropical Medicine, 2011.

17 Meade N, Islam T. Forecasting with growth curves: an empirical comparison. Int J Forecast 1995;11:199-215.

18 Zwietering $\mathrm{MH}$, Jongenburger I, Rombouts FM, et al. Modeling of the bacterial growth curve. Appl Environ Microbiol 1990;56:1875-81.

19 World Bank. Antiretroviral therapy coverage (\% of people living with HIV) | data. Available: http://api.worldbank.org/v2/country/all/ indicator/SH.HIV.ARTC.ZS?downloadformat=CSV\&date=2000:2017 [Accessed 01 Sep 2019].

20 UNAIDS. National HIV estimates file, 2020. UNAIDS. Available: https://www.unaids.org/en/dataanalysis/datatools/spectrum-epp [Accessed 21 Apr 2020].

21 UNAIDS. Methods for deriving UNAIDS estimates, 2018. UNAIDS. Available: https://www.unaids.org/sites/default/files/media_asset/ Estimates_methods_2018.pdf [Accessed 21 Apr 2020].

22 Avenir health. Available: https://www.avenirhealth.org/softwarespectrum.php [Accessed 21 Apr 2020].

23 UNAIDS. UNAIDS data 2019. Available: https://www.unaids.org/en/ resources/documents/2019/2019-UNAIDS-data [Accessed 13 Apr 2020].

24 World Bank Group. Population, total | data, 2017. Available: https:// data.worldbank.org/indicator/SP.POP.TOTL [Accessed 18 Nov 2017]

25 Newville M, Stensitzki T, Allen DB, et al. LMFIT: non-linear leastsquare minimization and curve-fitting for python. Zenodo 2014.

26 Spiess A-N, Neumeyer N. An evaluation of R2 as an inadequate measure for nonlinear models in pharmacological and biochemical research: a Monte Carlo approach. BMC Pharmacol 2010;10:6.

27 World Bank Group. World Development Indicators | DataBank - Prevalence of HIV, total (\% of population ages 15-49), 2017. Available: http://databank.worldbank.org/data/reports.aspx?source= 2\&series=SH.DYN.AIDS.ZS\&country= [Accessed 16 Aug 2019].

28 Kass RE, Raftery AE. Bayes factors. J Am Stat Assoc 1995;90:773-95.

29 Farahani M, Vable A, Lebelonyane R, et al. Outcomes of the Botswana national HIV/AIDS treatment programme from 2002 to 2010: a longitudinal analysis. Lancet Glob Health 2014;2:e44-50.

30 Gaolathe T, Wirth KE, Holme MP, et al. Botswana's progress toward achieving the 2020 UNAIDS 90-90-90 antiretroviral therapy and virological suppression goals: a population-based survey. Lancet HIV 2016;3:e221-30.

31 Binagwaho A, Farmer PE, Nsanzimana S, et al. Rwanda 20 years on: investing in life. Lancet 2014;384:371-5.

32 Chigwedere P, Seage GR, Gruskin S, et al. Estimating the lost benefits of antiretroviral drug use in South Africa. J Acquir Immune Defic Syndr 2008;49:410-5.

33 Johnson LF. Access to antiretroviral treatment in South Africa, 2004 2011. South Afr J HIV Med 2012;13:22-7.

34 UNAIDS. South Africa launches new plan to advance progress towards ending AIDS. Available: http://www.unaids.org/en/resources/ presscentre/featurestories/2017/april/20170403_south-africa-NSP [Accessed 22 Oct 2017]. 